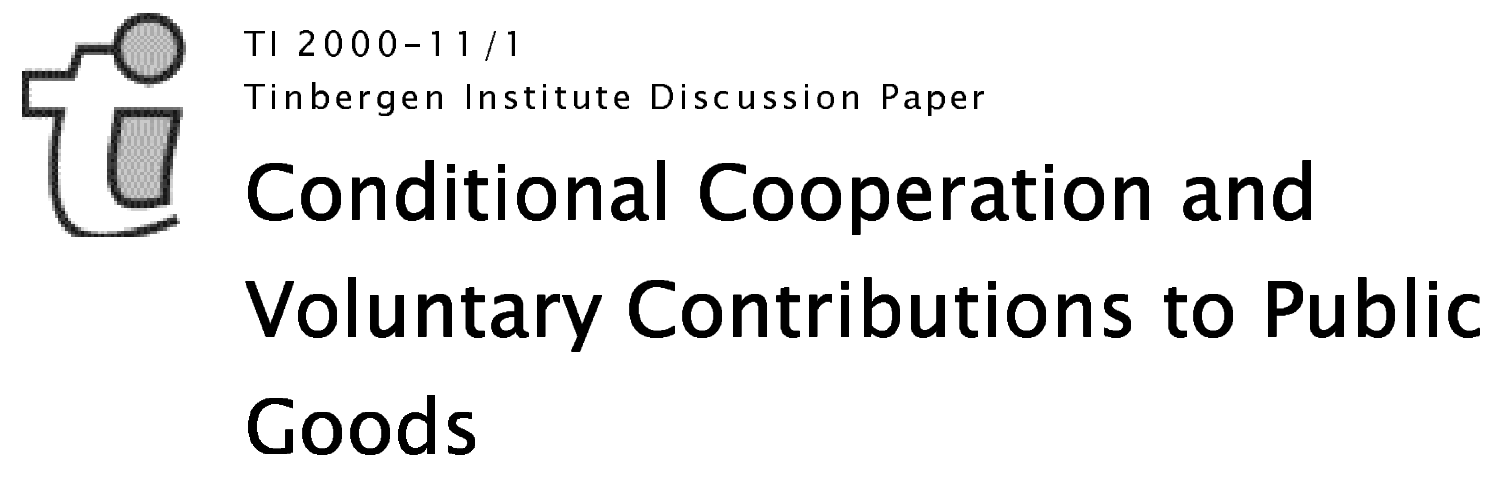

Claudia Keser

Frans van Winden 


\section{Tinbergen Institute}

The Tinbergen Institute is the institute for economic research of the Erasmus Universiteit Rotterdam, Universiteit van Amsterdam and Vrije Universiteit Amsterdam.

\section{Tinbergen Institute Amsterdam}

Keizersgracht 482

1017 EG Amsterdam

The Netherlands

Tel.: $\quad+31 .(0) 20.5513500$

Fax: $\quad+31 .(0) 20.5513555$

\section{Tinbergen Institute Rotterdam}

Burg. Oudlaan 50

3062 PA Rotterdam

The Netherlands

Tel.: $\quad+31 .(0) 10.4088900$

Fax: $\quad+31 .(0) 10.4089031$ 
Forthcoming in The Scandinavian Journal of Economics (accepted in May 1999)

\title{
CONDITIONAL COOPERATION AND VOLUNTARY CONTRIBUTIONS TO PUBLIC GOODS*
}

\author{
Claudia Keser and Frans van Winden \\ Universität Karlsruhe, Germany, and Universiteit van Amsterdam, The Netherlands
}

\begin{abstract}
We compare a partners condition where the same small group of subjects plays a repeated public good game to a strangers condition where subjects play this game in changing group formations. Subjects in the partners condition contribute from the first period on significantly more to the public good than subjects in the strangers condition. In the strangers condition, contributions show a continual decay, while in the partners condition, contributions fluctuate on a high level until they decrease in the final periods. We interpret subjects' behavior in terms of conditional cooperation which is characterized by both future-oriented and reactive behavior.
\end{abstract}

Keywords: Experimental Economics, Public Goods, Voluntary Contributions, Cooperation JEL-Code: C92, H41,

* The authors want to thank Simon Gächter, Roy Gardner, Alfred Müller, Reinhard Selten, Bodo Vogt, and two anonymous referees for their valuable comments on an earlier version of this paper. Thanks are also due to Otto Perdeck for programming the laboratory software. Financial support by the Netherlands' Organization for Scientific Research (NWO) and the Tinbergen Institute is gratefully acknowledged. This research was started while the first author was affiliated with the Tinbergen Institute and CREED as a fellow of the Human Capital and Mobility Program of the European Commission. Part of this research was done when the first author was a member of the Bureau d'Économie Théorique et Appliquée (BETA) at the Université Louis Pasteur in Strasbourg. 


\section{Introduction}

Since one of the earliest experiments on free riding by Bohm (1972) we know that people may be willing to voluntarily contribute to the provision of public goods. Extensive surveys by Ledyard (1995) and Davis and Holt (1993) of subsequent laboratory experiments show that, on average, subjects contribute between 40 and 60 percent of their endowment to a public good rather than use it for private activities. When the game is repeated, this is true at least for early repetitions. Later on, contributions typically decline, and eventually approach the free-riding level in the final repetitions. The actual level of the contributions depends on various factors, such as the number of players and the per capita rate of return of the public good relative to that of the private good. In this paper, we report on an experimental study which focuses on another factor which may be relevant in this context. This factor concerns the condition whether individuals are in a partners or strangers situation. In the partners condition the same group of subjects played this game repeatedly, while in the strangers condition subjects faced different group members in each repetition of the game. Our major concern is to gain insights into subjects' decision principles.

The existing experimental evidence regarding the (dis)similarity of the behavior of subjects in the partners and the strangers condition is mixed. In a much cited article, Andreoni (1988) observed that strangers contributed more to the public good than partners. A similar result was found by Palfrey and Prisbrey (1996). Weimann (1994), on the other hand, found no difference in the contribution levels of the two conditions. Both Weimann and Palfrey and Prisbrey observed a higher variance of contributions in the strangers condition than in the partners condition. Recently, Croson (1996) replicated Andreoni's design but obtained the 
opposite result. In her experiment, partners contributed more than strangers. Moreover, partners exhibited more variance in their contributions than strangers.

The reason for this mixed evidence may be that the results of these studies are based on few experimental sessions. Note that, strictly speaking, in the strangers condition, each session yields only one independent observation. ${ }^{1}$ Therefore, in our experiment we organized 6 strangers sessions, yielding 6 independent observations. Together with 10 independent observations in the partners condition, we have sufficient data to allow analyses based on nonparametric test statistics. Moreover, in contrast with the aforementioned experiments that used 10-fold repetitions of the public good game, our experiment consists of 25 repetitions. In our view, this provides a better opportunity for any difference in subjects' behavior to manifest itself.

After presenting the experimental design and procedures in Section 2 of this paper, we give the main results in Section 3. We first offer a rigorous statistical data analysis, based on strictly independent observations. Our results yield strong evidence for Croson's (1996) observation that partners, on average, contribute more than strangers. This appears to be the case both in the first period and over all periods. We do not observe a significant difference in the variation of individual contributions within the independent groups in the partners condition and the strangers condition. We do, however, observe significantly more variation in the contribution levels of the independent partners groups than in the contribution levels of the independent strangers groups. In both conditions, a strong positive correlation between average group contributions in the first period and average group contributions over all following periods is

\footnotetext{
Indirect links may be established: Through the interaction, subject A has an influence on subject $\mathrm{B}$, who influences subject $\mathrm{C}$ in a later repetition of the game, and so on.
} 
observed. The second part of our data analysis more closely examines individual subject behavior. One of the results is that we identify a significantly larger number of free riders, who contribute nothing to the public good, in the strangers condition than in the partners condition. Another result is that, whereas contributions in the strangers condition show a continual decay, contributions in the partners condition stay at a relatively high level before they drastically decrease toward the end of the game. We show that in both conditions this decrease is due to end-game behavior by the majority of subjects.

In Section 4 we offer a tentative explanation of individual behavior in the public good situation. This interpretation is based on the concept of conditional cooperation, with the two aspects of future-oriented and simple reactive behavior. The behavioral difference between partners and strangers shows largely in the first period. In contrast to strangers, partners can anticipate a prolonged interaction with the same subjects and this has a noticeable influence on their initial contribution decisions. Future-orientation also shows up in the end-game behavior in both conditions. In the final periods, subjects foresee or become aware of the ending of their interaction. After the first period and before the end game, subjects in both conditions show qualitatively the same simple reactive behavior, characterized by reciprocity.

In Section 5 we discuss in how far various theories that incorporate motivational aspects in the standard neoclassical framework could explain the observed behavior. The paper is concluded in Section 6. 


\section{The experiment}

In the experiment, subjects played 25 repetitions of the following constituent game. Four subjects form a group. Each of the subjects is endowed with 10 tokens, which have to be allocated between two activities, called $\mathrm{X}$ and $\mathrm{Y}$. Activity $\mathrm{X}$ has, for each subject, the nature of a private good. Each token allocated to activity $\mathrm{X}$ earns the subject an individual payoff of 10 Dutch cents. Activity Y has the nature of a public good. Each token allocated by any subject of the group to activity Y yields each subject a payoff of 5 Dutch cents. Thus, a subject may receive a payoff from this activity without having contributed to it. The aggregate payoff from both activities determines a subject's payoff for the constituent game.

The game-theoretic solution to the constituent game is straightforward. Whatever the decisions of the other subjects, a subject's individual return from activity $\mathrm{X}$ exceeds his individual return from activity $\mathrm{Y}$. Thus, each subject has a dominant strategy to contribute all tokens to activity $\mathrm{X}$, assuming own-payoff maximization. Using backward induction, the unique subgame-perfect equilibrium of the repeated game is for each subject to contribute nothing to activity $\mathrm{Y}$ in each repetition. The maximum payoff to the entire group is attained, however, if in each repetition all subjects contribute all of their tokens to activity Y.

The computerized experiment was run at the CREED laboratory of experimental economics at the University of Amsterdam. Subjects were students majoring in economics (about 50 percent) and various other fields. In total, we ran 6 strangers sessions and 2 partners sessions. In the beginning of each session, 20 subjects were randomly divided into 5 groups of 4 subjects. In contrast with the partners sessions, where subjects stayed in these groups during all 25 
repetitions, in the strangers sessions new groups were randomly formed in each of the following 24 repetitions. Subjects were never informed about the identity of the other subjects in the group. In both the strangers sessions and the partners sessions, at the end of each repetition each subject was informed about the total contribution to activity $\mathrm{Y}$ in his or her own group in the repetition just finished. No information was given about the others' individual contributions.

Before the experiment started, ${ }^{2}$ written instructions (available upon request) were read aloud. Then, the subjects were given the opportunity to ask questions before they individually had to go through additional, computerized instructions. These included exercises to make sure that the subjects understood the rules of the game. No examples of allocation decisions were given in these exercises in order not to bias the subjects in any way. The allocation of tokens on which the exercises were based had to be chosen by the subjects themselves. Each subject was seated at a computer terminal in a separate cubicle. During the experiment each subject had the results of the games he or she was involved in available on the computer screen. Communication, other than through the decisions made, was not allowed. At the end of the experiment, each subject privately received, in cash, his or her payoff from the experiment. The average payoff, earned in about one and a half hour, was nearly 36 Dutch guilders in the partners condition and 30 Dutch guilders in the strangers condition.

\footnotetext{
${ }^{2}$ Prior to the experiment, the subjects took part in a test on social value orientation. In this paper, we make no use of the results of the test. For a description of the test on social value orientation, see Keser and van Winden (1996) or Offerman et al. (1996).
} 


\section{Results}

In the first part of this section, we present a rigorous statistical data analysis focusing on the partners-strangers comparison. This part of the analysis will, with one exception, be based on data for the independent subject groups. In the second part of this section, we try to identify some features of individual behavior, in both the partners and the strangers condition. Following Siegel (1987), nonparametric statistical test methods will be used.

\section{Major results}

Figure 1 shows the time paths of the average contributions to the public good (activity Y) in the strangers condition and in the partners condition. We see that on average subjects in both conditions make significant contributions to the public good. Moreover, partners contribute more than strangers in each period. The average contribution, over all repetitions and all subjects, is 4.53 tokens (standard deviation 3.95) in the partners condition and 1.90 tokens (standard deviation 3.05) in the strangers condition.

To show that this difference in the contribution levels is statistically significant, consider Table 1. The second column of this table presents, for each independent subject group, the average contribution to the public good over all 25 repetitions. Applying a two-tailed MannWhitney $U$ test, we can reject the null hypothesis that average contribution levels are the same at the 5 percent significance level. We conclude that the contribution levels of strangers and partners are significantly different. 
Figure 1 further suggests that partners start out, already in the first period, with a higher contribution level than strangers. Applying a Mann-Whitney U test, we can reject the null hypothesis of no difference at the 5 percent level (two-sided test). We conclude that partners significantly tend to contribute more in the first period than strangers.

From Table 1 it can also be observed that average contributions to the public good vary more among the independent partners groups than among the independent strangers groups. To demonstrate, we consider for each independent partners group the absolute deviation of its average contribution from the grand average of 4.53 and, similarly, for each independent strangers group the absolute deviation of its average contribution from the grand average of 1.90 . These values are reported in column 3 of Table 1. Applying a Mann-Whitney U test, we can reject the null hypothesis of no difference at the 5 percent level (two-sided test). As the average absolute deviation is 2.12 in the partners condition and 0.52 in the strangers condition, we conclude that the deviation tends to significantly be higher in the partners condition than in the strangers condition. ${ }^{3}$

Having observed significantly more variation among the contributions of independent partners groups than among the contributions of independent strangers groups, we now ask whether the variation within the partners groups is different from the variation within the strangers groups. Column 4 of Table 1 shows for each independent subject group the standard deviation of contributions to the public good. Another interesting measure of variation within a

\footnotetext{
${ }^{3}$ For further evidence, we apply a Moses test for the hypothesis that the average contributions of partners groups are more extreme than those of the strangers groups. The null hypothesis that there is no difference in the variation of the average contributions between the groups in the partners and the strangers condition can be rejected at the 1 percent significance level.
} 
subject group is presented in column 5 of Table 1. It is a measure of stability of the individual decisions. A subject's individual stability measure is defined as the average absolute change in his contributions from one period to the next. The group stability measure is calculated as the mean of the group members' individual stability measures. Applying Mann-Whitney U tests we can reject at the 5 percent level neither the null hypothesis that the standard deviations of the contributions within the independent subject groups tend to be the same in both conditions nor the null hypothesis that the group stability measures tend to be the same in both conditions. Thus, we have no statistical evidence for a significant difference in the variation of contributions within the independent subject groups in both conditions. ${ }^{4}$

These results show that a significant behavioral difference is induced by the two conditions. This difference does not only manifest itself in the aggregate contribution levels, showing that partners contribute more than strangers. It also shows up in the variation of the decisions of the independent subject groups. In the partners condition we observe more variation between the group contribution levels than in the strangers condition. The high variation between the group contributions in the partners condition results from the coexistence of extremely cooperative groups and of groups where only very little is contributed to the public good. One might argue that this result is not interesting because in the strangers groups extremely high and low contributions are likely to cancel out due to the aggregation over 20 subjects. If this were the case, however, we should expect a higher standard deviation of contributions in the strangers groups than in the partners groups. This is, however, not what we observe (see column 4 of Table

\footnotetext{
${ }^{4}$ Note that, if anything, the variation in the partners condition tends to be greater than in the strangers condition. This result is in contrast to those of Palfrey and Prisbrey (1996) and Weiman (1994) but in line with the observation made by Croson (1996).
} 
1).

Common to both conditions is the observation that the decisions of the group members in the first period are decisive for the average contribution level of the group over the remaining repetitions of the game. We find a strongly positive correlation between the average contributions of the independent subject groups in the first period and the average contributions of the independent subject groups over all but the first periods. The Spearman rank correlation coefficient is 0.91 for the partners and 0.94 for the strangers. Both rank correlation coefficients are significantly positive at the 1 percent level (one-sided testing).

\section{Further results}

Figure 2 shows the distribution of individual contributions over all 25 periods. In the strangers condition, we find a distribution with a unique mode at zero, while a bimodal distribution is found in the partners condition with modes at zero and ten. Applying a two-sided Kolmogorov-Smirnov test, we can reject the null hypothesis of no difference in the distributions at the 1 percent level. This yields further evidence of more variation among the individual decisions of partners than among the individual decisions of strangers.

Another observation showing a difference between the two conditions concerns free-

riding. As Table 2 shows, only 1 of the 40 subjects (2.5 percent) in the partners condition and 24 of the 120 subjects (20 percent) in the strangers condition play the dominant strategy of zero contribution in all periods. We call them strong free riders. Moreover, another 12 of the 40 subjects (30 percent) in the partners condition and another 42 of the 120 subjects ( 35 percent) in 
the strangers condition make zero contributions in more than half but not all of the periods (i.e. in at least 13 but less than 25 periods.) We call them weak free riders. Thus, 33 percent of the subjects in the partners condition and 55 percent of the subjects in the strangers condition are (weak or strong) free riders making zero contributions in more than half of the periods. Dividing our subjects into (weak or strong) free riders and others and applying a $\chi^{2}$ test, we can reject at the 5 percent significance level (two-sided test) the null hypothesis of no difference. We conclude that free riders tend to occur more often in the strangers condition than in the partners condition.

Table 2 also reports the number of subjects who contribute all ten tokens to the public good in all periods (strong cooperators), as well as the number of subjects who contribute ten tokens in more than half but not in all of the periods (weak cooperators). Only in the partners condition do we observe a strong cooperator. Moreover, we find 7 weak cooperators (17.5 percent) in the partners condition and only 3 weak cooperators ( 3 percent) in the strangers condition. Dividing our subjects into (weak or strong) cooperators and others and applying a $\chi^{2}$ test, we can reject at the 1 percent significance level (two-sided test) the null hypothesis of no difference. We conclude that cooperators tend to occur more often in the partners condition than in the strangers condition.

Another interesting observation, illustrated in Figure 1, is that only in the strangers condition do we observe the continual downward trend in the average contribution level which is considered as typical for this type of public good game. In the partners condition contributions fluctuate at a relatively high level until they decrease strongly toward the end of the game. Especially in the partners condition, Figure 1 leads us to expect an end-game behavior as 
described by Stoecker (1983) and Selten and Stoecker (1986) for finitely repeated prisoner's dilemma games. For our public good game, we define a subject's end-game behavior as a sequence of one or more zero contributions—counted from the final period of the game-given that positive amounts have been contributed in at least half of the prior periods. According to this definition, there are 24 subjects in the partners condition and 62 subjects in the strangers condition who show end-game behavior (see the last column of Table 2). Considering only those subjects who are neither strong free riders nor strong cooperators it is 63 percent of the partners and 64 percent of the strangers who exhibit end-game behavior. We have no statistical evidence for a significant difference in the tendency to engage in end-game behavior in the two conditions.

\section{Toward a dynamic theory: Conditional cooperation}

Our results show that in each period, including the first one, partners on average contribute more to the public good than strangers. A continual downward trend is observed in the strangers condition but not in the partners condition. In the final period(s) of the game, both partners and strangers tend to contribute nothing to the public good. These so-called end games tend to be longer in the strangers condition than in the partners condition. There is no statistical evidence that the stability of individual contributions within the independent subject groups is different between the partners and the strangers conditions. Based on these results and those of related studies, we suggest an interpretation of subjects' behavior in the public good situation in terms of conditional cooperation. We distinguish between two aspects of conditional cooperation. One is future-oriented behavior. The other is simple reactive behavior. 
As future-oriented behavior we define aspects of subjects' behavior that are induced by their perception of future interaction. Evidence of this type of behavior particularly shows up in the partners sessions, where contribution levels often sharply fall in the final period(s). Possibly, subjects near the end of the game realize that investment in their relationship with other group members is not worthwhile any longer. Or subjects may anticipate such a reasoning by others. Assuming that subjects are rather myopic, they will at most look a few periods ahead when deliberating on their investments (see Isaac, Walker and Williams 1994). This may be the reason why this behavior occurs only toward the end of the game. Other evidence of future-oriented behavior, but now regarding the beginning of play, is provided by the fact that already in the first period we observe a significant difference in the contribution levels of the two conditions. An explanation can be found in the study by Keser (1997) where subjects designed complete strategies for playing a public good game in a computer tournament. The strategies suggest that the majority of subjects signal an interest in cooperation in the first period. Thereafter, behavior is simply oriented toward the observed average contribution of the other group members in the previous period until in the final periods end-game behavior takes over. From a cognitive point of view, it is plausible that the propensity to signal a willingness to cooperate is stronger in the partners sessions than in the strangers sessions. Moreover, the literature suggests that individuals show a propensity to identify with the group they belong to. As a consequence, an interest in group success is substituted for or added to their interest in individual success (for discussion and experimental evidence, see Brewer and Kramer 1986, Dawes and Thaler 1988, Dawes, Van de Kragt and Orbell 1988, Offerman 1997, Simon 1993, Taylor and Moghaddam 1994). Obviously this factor is more relevant for the partners sessions than for the strangers sessions. This might 
also provide an explanation of the difference in initial contribution levels.

All in all, these results suggest that cooperation is dependent on the subjects' perception of future interaction. The tendency to cooperate is greater when subjects anticipate prolonged interaction with others as members of a group, as holds for the partners sessions up to the final periods of play. ${ }^{5}$

The second aspect of conditional cooperation concerns reactive behavior. Supportive in this respect is Keser's (1997) finding, noted above, that behavior in a public good game is oriented toward the average behavior of the other group members in the previous period. This kind of behavior is in line with the principle of reciprocity that was explicitly used by Axelrod (1984) as an explanation for the observed cooperation in a prisoner' s dilemma situation where people tend to reciprocate cooperation with cooperation and defection with defection. Reciprocity is often referred to in the experimental literature (see, e.g., Fehr, Kirchsteiger and Riedl 1993, Fehr, Gächter and Kirchsteiger 1997, Hoffman, McCabe and Smith 1996). Our hypothesis is that also in our experiment reciprocity is at work.

To test this hypothesis, we need to define reciprocal behavior in our experiment. Recall that our subjects have information about the total contribution of the others in the group, but not about the individual contributions. Thus, a natural way to formalize reciprocity in our environment seems to be the following qualitative decision rule: If a subject intends to change his decision from one period to the next, he changes it in the direction of the other group members' average contribution in the previous period. This means that he increases his

\footnotetext{
Further support is provided by Cotterell et al. (1992, p.658): "It has been found that more resources are allocated to partners with whom future interaction is expected."
} 
contribution if it was below the average of the others, and he decreases his contribution if it was above the average. In our experiment more than half of the observations are of no change (52 percent in the partners condition and 62 percent in the strangers condition). However, in cases where a change occurs, our rule yields a remarkably good prediction of the direction of the change. This can be seen in Tables 3 and 4. The first three columns of these tables show-for the partners and the strangers condition, respectively-how often a subject could observe that his or her own contribution was above (situation 1), below (situation 2), or equal to (situation 3) the average contribution of the others. The last three columns show how often it occurred that a subject reacted with an increase, a decrease, or no change in each situation. To test our simple qualitative decision rule, which predicts the direction of a change if a change is intended at all, we consider the reactions increase and decrease in situations 1 and 2 . If the decision rule makes the right predictions, we should observe relatively more increases than decreases in situation 2 , and relatively more decreases than increases in situation 1 . Applying the $\chi^{2}$ test for the null hypothesis that right and wrong predictions are equally likely, we may reject the null hypothesis for each condition at the 1 percent significance level. We conclude that reactive behavior in this simple form of reciprocity is an important aspect of behavior.

Interestingly, this evidence of reciprocity appears equally strong in the two conditions About 80 percent of the observed changes are in the predicted direction. ${ }^{6}$ According to Gouldner (1960; also cited in Pruitt 1968) reciprocity can be attributed to norm reciprocity and/or tactical reasoning. In the latter case, reciprocity is considered to serve a strategic purpose which is to

\footnotetext{
${ }^{6}$ Furthermore, in the situation that one's own contribution was equal to the average contribution of the other subjects (situation 3), we observe that if a change occurred it was significantly more often an increase than a decrease in both conditions.
} 
encourage others to provide further. Pruitt tested both hypotheses and found experimental evidence for norm reciprocity only. Our results seem to support Pruitt's findings. If the reciprocity observed in our experiment were mainly due to tactical reasoning, then it should have been more apparent in the partners than in the strangers condition.

A noticeable difference between partners and strangers concerns the number of times that subjects are observed to change their contributions. In the partners condition, subjects change their contributions almost equally often in situation 1 (230 times) and situation 2 (193 times). In the strangers condition, however, there are many more observations of a change in situation 1 (619) than in situation 2 (378). An obvious reason is the relative large number of free riders in the strangers condition (see above) which explains the relatively large number of the no change cases in situation 2 of this condition. Incidentally, this asymmetry offers an explanation for the observed continual decay in the average contribution level in the strangers condition, and the absence of such a decay in the partners condition.

We have given a dynamic interpretation of subjects' behavior in the public good situation in terms of conditional cooperation. To what extent some existing theories of cooperative behavior can explain our experimental results is discussed in the following section.

\section{Other theories}

Besides the standard game-theoretic solution which we showed not to be adequate for describing our experimental results, there exist other approaches in the literature which might be relevant for our public good situation. One of these is the reputation model proposed by Kreps et 
al. (1982). Other approaches try to account for persistent deviations from the standard neoclassical theory by the incorporation of various motivational aspects.

Reputation building: Andreoni (1988) expected partners to make higher voluntary contributions to the public good than strangers due to what he calls the strategies hypothesis. He suggests that partners, contrary to strangers, might have an incentive to play strategically in the sense of Kreps et al. (1982). If a subject is not sure whether the other subjects fully understand the structure of the game, then, in early repetitions of the game, he has no interest in educating the others to play the dominant strategy. This would imply a relatively high contribution level in the early periods which decreases when the end draws near. Similarly, we could assume that a subject, who is not sure whether or not the others are of the reciprocal altruistic type, might have an interest to build up in early periods of the game a reputation of being a reciprocal altruist himself. However, the individual reputation building hypothesis requires that subjects are informed about the individual contributions of the others, which is not the case in our experiments. Furthermore, this hypothesis requires that the same group of subjects stays together, which does not hold for the strangers condition. Thus, it is impossible to verify the motivational relevance of this kind of strategic play in our experiments. ${ }^{7}$

Altruism: An alternative explanation of why people cooperate is altruism: People may be motivated by "taking pleasure in others' pleasure" (Dawes and Thaler 1988). A theory of altruism is presented, for example, by Andreoni and Miller (1996). They assume that an altruistic player's utility increases not only in his own payoff but also in the other players' payoffs. This implies

\footnotetext{
7 Some support for strategic play in the sense of Kreps et al. (1982) has been found in experiments specially designed for the examination of such behavior in various social dilemma
} 
unconditional cooperation. However, a theory based on altruistic motives for giving cannot be adequate to describe the observed behavior in the public goods experiments. Recall that in the final period of the game we observe that the majority of subjects contribute nothing or very little to the public good. But why should altruistic motives for contributing vanish over time? It is not surprising that Andreoni and Miller (1996) consider contributions observed in the first periods of public goods games in order to find evidence in favor of their theory.

Reciprocity: A theory of reciprocity is presented, for example, by Rabin (1993). Reciprocity (or, fairness) is defined as the desire to be kind to those who signal kindness through their actions and to hurt those who signal hostility through their actions. Applied to the public good situation, this theory predicts positive contributions if there are reciprocal players who believe that other players will contribute, too. Thus, our experimental results are compatible with these theories of reciprocity.

Equity or inequality aversion: Bolton and Ockenfels (forthcoming) present a theory of equity. It is based on the assumption that "along with the pecuniary payoff, individuals are motivated by a 'relative' payoff, a measure of how the pecuniary payoff compares to that of other players." Similarly, Fehr and Schmidt (forthcoming) present a theory of inequality aversion. Their theory is based on the assumption that, to some extent, people dislike inequality in payoffs and that they dislike inequality more if it is to their disadvantage than if it is to their advantage. Applied to the public good situation, as long as inequality-averse players believe that other players are contributing, they are willing to contribute, too. This result holds also for the theory of Bolton and Ockenfels. Thus, our results are compatible with both theories. Note, that similar

games (Andreoni and Miller 1993, Gächter and Falk 1997, McKelvey and Palfrey 1992, Cooper, 
to the theory of reciprocity, these theories are based on preference assumptions which change the dilemma game, with its unique inefficient equilibrium, into a coordination game with multiple equilibria. To choose among these equilibria, players have to form beliefs about the other players' choices. If they update the beliefs in the light of what they observed in the earlier rounds of the game, the contributions that we observe in the experiments make sense, not only in the partners condition but also in the strangers condition. None of these theories can, however, explain the observed difference in the initial contribution level of partners and strangers. Neither can they explain the (different) end game behavior of partners and strangers. ${ }^{8}$

\section{Conclusion}

Our results show statistically significant differences of aggregate and individual behavior in the partners and the strangers condition. Among the subjects in the strangers condition, we find significantly more free riders and fewer cooperators than among the subjects in the partners condition. In the aggregate, strangers contribute less to the public good than partners. The basis for this difference in contributions is created in the first period. The first period contribution level in an independent subject group appears to be decisive for the contribution level in that group in the remaining periods.

We suggest that typical individual behavior in our experiment is a manifestation of conditional cooperation, characterized by future-oriented and simple reactive behavior. After the

deJong, Forsythe and Ross 1996).

${ }^{8}$ Similar problems hold for Palfrey and Prisbrey's $(1996,1997)$ explanation in terms of decision errors and the "cooperative gain seekers" model proposed by Brandts and Schram (1996). 
first period, qualitatively the same behavior is observed in both the partners and the strangers condition. It seems that the significant difference between the two conditions regarding the average contribution levels is largely due to the significant behavioral difference in the first period. In our view, the clue to this difference is to be sought in the different motivational and cognitive processes triggered by the partners and strangers environments, which lead to relatively more cooperative behavior in the partners condition and more free riding in the strangers condition.

\section{References}

Andreoni, J. (1988), Why free ride?, Journal of Public Economics 37, 291-304.

Andreoni, J. and Miller, J. H. (1993), Rational cooperation in the finitely repeated prisoner's dilemma: experimental evidence, Economic Journal 103, 570-585.

Andreoni, J. and Miller, J. H. (1996), Giving according to GARP: an experimental study of rationality and altruism, Working Paper, University of Wisconsin-Madison.

Axelrod, R. M. (1984), The evolution of cooperation, Basic, New York.

Bohm, P. (1972), Estimating demand for public goods: An experiment, European Economic Review 3, 111-130.

Bolton, G. E. and Ockenfels, A. (forthcoming), ERC: A theory of Equity, Reciprocity and Competition, American Economic Review.

Brandts, J. and Schram, A. (1996), Cooperative gains or noise in public goods experiments: Applying the contribution function approach, Tinbergen Institute Discussion Paper TI 96-81/1, University of Amsterdam.

Brewer, M. B. and Kramer, R. M. (1986), Choice behavior in social dilemmas: Effects of social identity, group size, and decision framing, Journal of Personality and Social Psychology 50, 543545 .

Cooper, R., deJong, D. V., Forsythe, R. and Ross, T. W. (1996), Cooperation without reputation: Experimental evidence from Prisoner's dilemma games, Games and Economic Behavior 12, 187 - 
218.

Cotterell, N., Eisenberger, R. and Speicher, H. (1992), Inhibiting effects of reciprocation wariness on interpersonal relationships, Journal of Personality and Social Psychology 62, 658668.

Croson, R. (1996), Partners and strangers revisited, Economics Letters 53, 25-32.

Davis, D. and Holt C. (1993), Experimental economics, Princeton University Press, Princeton, NJ.

Dawes, R. M. and Thaler, R. H. (1988), Anomalies: Cooperation, Journal of Economic Perspectives 2, 187-197.

Dawes, R. M., Van de Kragt, A. J. C. and Orbell, J. M. (1988), Not me or thee: The importance of group identity in eliciting cooperation in dilemma situations: Experimental manipulations, Acta Psychologica 68, 83-97.

Fehr, E., Gächter, S. and Kirchsteiger, G. (1997), Reciprocity as a contract enforcement device: Experimental evidence, Econometrica 65, 833-860.

Fehr, E., Kirchsteiger, G. and Riedl, A. (1993), Does fairness prevent market clearing? An experimental investigation, Quarterly Journal of Economics 108,437-460.

Fehr, E. and Schmidt, K. M. (forthcoming), A theory of fairness, competition, and cooperation, Quarterly Journal of Economics.

Gächter, S. and Falk, A. (1997), Reputation or reciprocity, Working Paper, University of Zürich.

Gouldner, A. W. (1960), The norm of reciprocity: A preliminary statement, American Sociological Review 25, 161-178.

Hoffman E., McCabe, K. and Smith, V. (1996), Behavioral foundations of reciprocity: Experimental economics and evolutionary psychology, draft.

Isaac, R. M., Walker, J. M. and Williams, A. W. (1994), Group size and the voluntary provision of public goods, Journal of Public Economics 54, 1-36.

Keser, C. (1997), SUPER: Strategies Used in Public goods Experimentation Rounds, Working Paper No. 97/24, Sonderforschungsbereich 504, University of Mannheim.

Keser, C. and van Winden, F. (1996), Social motivation and voluntary contributions to a public good, Working Paper, University of Amsterdam. 
Kreps, D., Milgrom, P., Roberts, J. and Wilson, R. (1982), Rational cooperation in the finitely repeated prisoners' dilemma, Journal of Economic Theory 27, 245-252.

Ledyard, J. (1995), Public goods: A survey of experimental research, in A. E. Roth and J. Kagel, (eds.), The Handbook of Experimental Economics, Princeton University Press.

McKelvey, R. D. and Palfrey, T. R. (1992), An experimental study of the centipede game, Econometrica 60, 803-836.

Offerman, T. (1997), Beliefs and decision rules in public good games, Kluwer Academic Publishers, Dordrecht.

Offerman, T., Sonnemans, J. and Schram, A. (1996), Value orientation, expectations, and voluntary contributions in public goods, Economic Journal 106, 817-845.

Palfrey, T. and Prisbrey, J. (1996), Altruism, reputation and noise in linear public goods experiments, Journal of Public Economics 61, 409-427.

Palfrey, T. and Prisbrey, J. (1997), Anomalous behavior in public goods experiments: How much and why?, American Economic Review 87, 829-846.

Pruitt, D. G. (1968), Reciprocity and credit building in a laboratory dyad, Journal of Personality and Social Psychology 8, 143-147.

Rabin, M. (1993), Incorporating fairness into game theory and economics, American Economic Review 83, 1281-1302.

Selten R. and Stoecker, R. (1986), End behavior in finite prisoner' s dilemma supergames, Journal of Economic Behavior and Organizations 7, 47-70.

Siegel, S. (1987), Nichtparametrische statistische Methoden, 3. Auflage, Fachbuchhandlung für Psychologie, Verlagsabteilung, Eschborn bei Frankfurt am Main.

Simon, H. A. (1993), Altruism and economics, American Economic Review 83, 156-161.

Stoecker R. (1983), Das erlernte Schlußverhalten-eine experimentelle Untersuchung, Zeitschrift für die gesamte Staatswissenschaft 139, 100-121.

Taylor, D. M. and Moghaddam, F. M. (1994), Theories of intergroup relations-international social psychological perspectives, second edition, Praeger, Westport.

Weimann, J. (1994), Individual behavior in a free riding experiment, Journal of Public Economics 54, 185-200. 
Table 1:

Average contribution and standard deviation of each independent subject group, partners groups (P1 to P10) and strangers groups (S1 to S6), ordered with respect to the average contribution level.

\begin{tabular}{|c|c|c|c|c|}
\hline group & $\begin{array}{c}\text { average } \\
\text { contribution }\end{array}$ & $\begin{array}{c}\text { absolute } \\
\text { deviation from } \\
\text { average }\end{array}$ & $\begin{array}{c}\text { standard } \\
\text { deviation } \\
\text { of contribution }\end{array}$ & $\begin{array}{c}\text { group } \\
\text { stability } \\
\text { measure }\end{array}$ \\
\hline S1 & 2.61 & 0.71 & 3.90 & 1.56 \\
S2 & 2.60 & 0.70 & 3.51 & 1.31 \\
S3 & 2.02 & 0.12 & 3.07 & 1.49 \\
S4 & 1.98 & 0.08 & 2.83 & 1.34 \\
S5 & 1.24 & 0.66 & 2.38 & 0.86 \\
S6 & 0.98 & 0.92 & 1.78 & 0.76 \\
\hline average & 1.90 & 0.52 & 2.92 & 1.22 \\
\hline P1 & 9.45 & 4.92 & 2.22 & 0.36 \\
P2 & 7.30 & 2.77 & 3.83 & 2.08 \\
P3 & 5.80 & 1.27 & 2.73 & 2.28 \\
P4 & 5.36 & 0.83 & 4.20 & 1.68 \\
P5 & 5.32 & 0.79 & 3.10 & 2.33 \\
P6 & 3.89 & 0.64 & 3.21 & 1.66 \\
P7 & 3.08 & 1.45 & 3.67 & 2.43 \\
P8 & 2.69 & 1.84 & 2.18 & 1.85 \\
P9 & 1.37 & 3.16 & 2.40 & 0.96 \\
P10 & 1.00 & 3.53 & 2.76 & 0.85 \\
\hline average & 4.53 & 2.12 & 3.03 & 1.65 \\
\hline
\end{tabular}

${ }^{\mathrm{a}}$ For definition, see text.

Table 2:

Overview of some observed characteristics of individual behavior.

\begin{tabular}{|c|c|c|c|c|c|c|}
\hline \multirow[b]{2}{*}{ condition } & \multirow[b]{2}{*}{$\begin{array}{l}\text { total \# } \\
\text { subjects }\end{array}$} & \multicolumn{5}{|c|}{ total \# subjects contributing } \\
\hline & & $\begin{array}{c}\text { always } \\
\text { zero }\end{array}$ & $\begin{array}{c}\text { mostly }^{\mathrm{a}} \\
\text { zero }\end{array}$ & $\begin{array}{c}\text { always } \\
\text { ten }\end{array}$ & $\begin{array}{c}\text { mostly }^{\mathrm{a}} \\
\text { ten }\end{array}$ & $\begin{array}{l}\text { with end } \\
\text { game }^{\text {b }}\end{array}$ \\
\hline partners & 40 & 1 & 12 & 1 & 7 & 24 \\
\hline strangers & 120 & 24 & 42 & - & 4 & 62 \\
\hline
\end{tabular}

${ }^{\mathrm{a}}$ In more than half of the periods but not in all periods.

${ }^{b}$ For definition of end-game behavior, see text. 
Table 3:

Partners condition: Number of times that a subject observed his contribution above (situation 1), below (situation 2) or equal to (situation 3 )

the average contribution of the others, and subjects' reactions in these situations.

\begin{tabular}{|c|c|c|c|c|c|}
\hline situation & $\begin{array}{c}\text { own } \\
\text { contribution }\end{array}$ & $\begin{array}{c}\# \\
\text { observations }\end{array}$ & increase & decrease & no change \\
\hline 1 & > others' & 387 & 42 & 188 & 157 \\
\hline 2 & < others' & 379 & 161 & 32 & 186 \\
\hline 3 & = others' & 194 & 30 & 10 & 154 \\
\hline
\end{tabular}

Table 4:

Strangers condition: Number of times that a subject observed his contribution above (situation 1), below (situation 2) or equal to (situation 3 ) the average contribution of the others, and subjects' reactions in these situations.

\begin{tabular}{|c|c|c|c|c|c|}
\hline Situation & $\begin{array}{c}\text { own } \\
\text { contribution }\end{array}$ & $\begin{array}{c}\# \\
\text { observations }\end{array}$ & increase & decrease & no change \\
\hline 1 & > others' & 926 & 111 & 508 & 307 \\
\hline 2 & < others' & 1491 & 320 & 58 & 1113 \\
\hline 3 & = others' & 463 & 69 & 15 & 379 \\
\hline
\end{tabular}




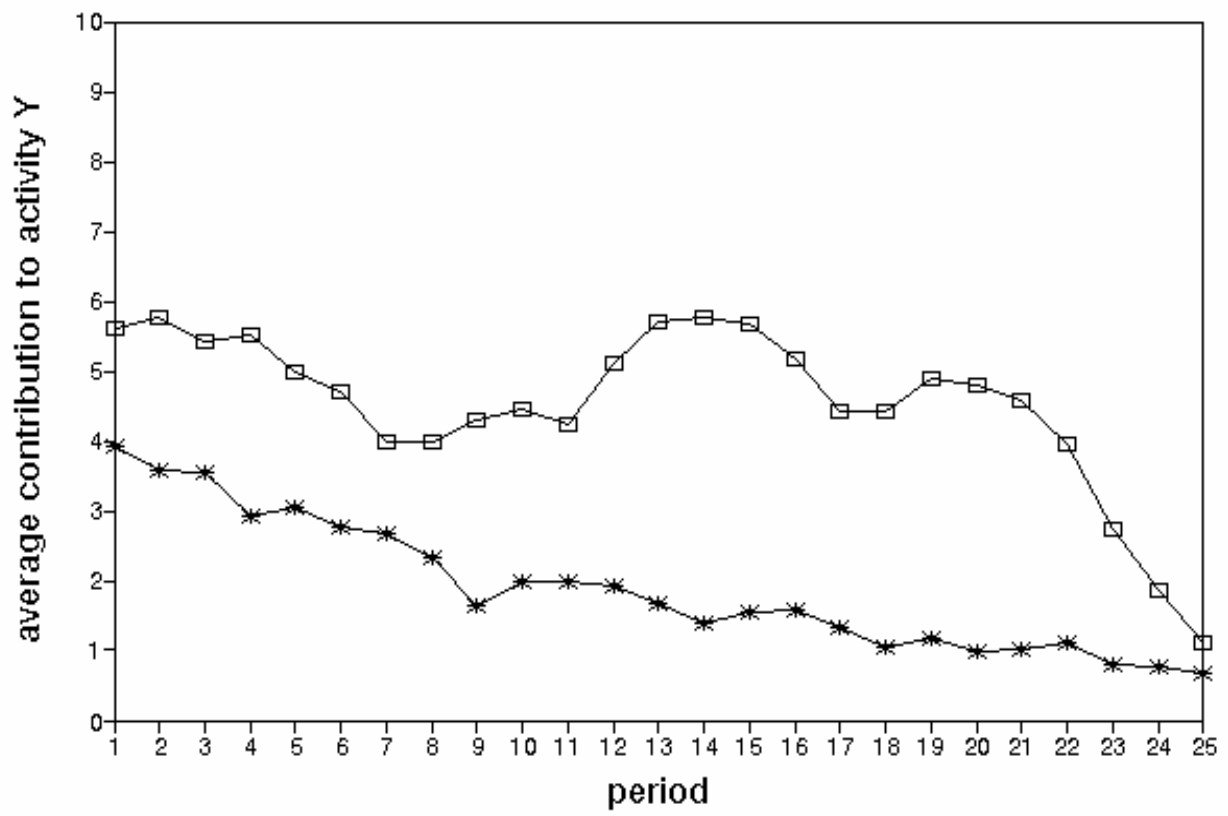

$\square$ partners $*$ strangers

Figure 1: Time paths of average contributions to the public activity $\mathrm{Y}$ (partners / strangers). 


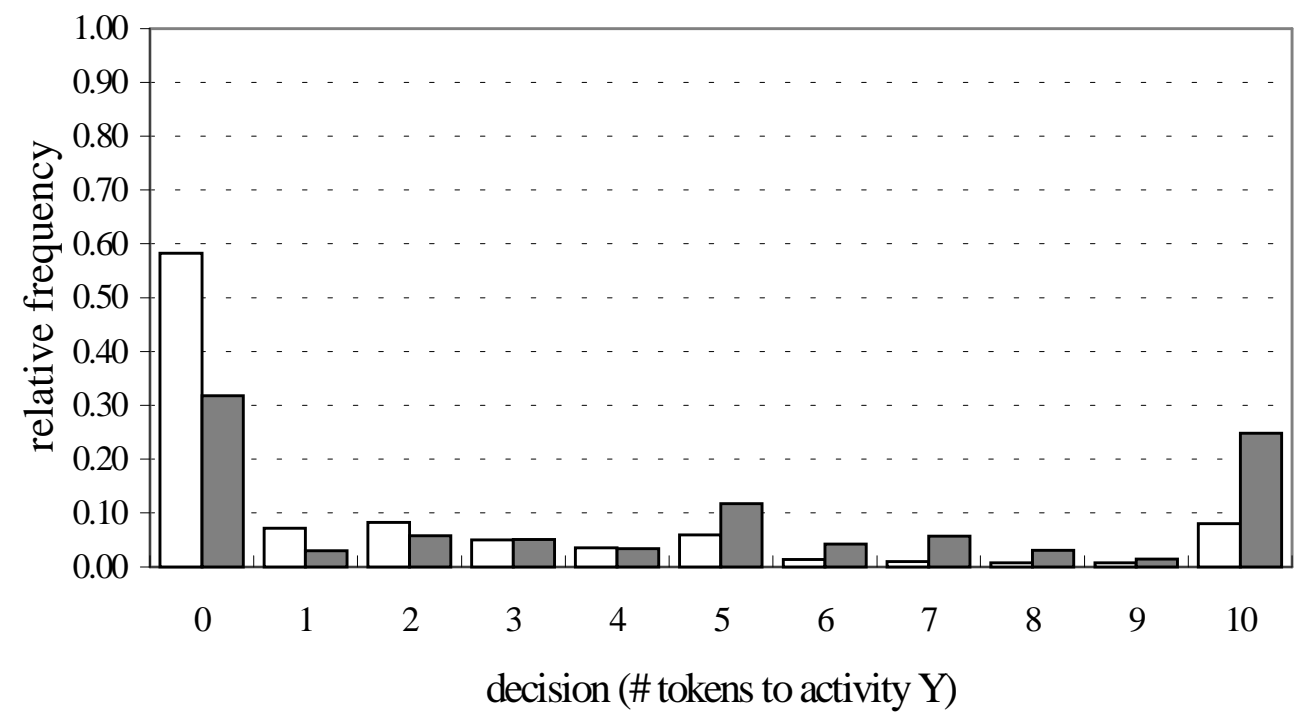

$\square$ strangers $\square$ partners

Figure 2: $\quad$ Individual contribution decisions over all periods (partners /strangers). 